\title{
Norms of restricted color association
}

\author{
ROBERT E. WARREN \\ Columbia University, New York, New York 10027
}

\begin{abstract}
Increasing use of the Stroop color-word test to assess the activation of words in memory requires a pool of words whose color associations are known. To provide such a pool, 100 Ss were asked to indicate which of four common colors (red, blue, yellow, or green) was most closely associated with each of 72 words. Normative response tables of the obtained associations are provided.
\end{abstract}

In the Stroop task, items are presented printed in color and the S's task is to name the color as quickly as possible. In the standard version of the test, the items are either rows of Xs or antagonistic color words, e.g., the word RED printed in blue ink. Typically, it takes longer to name the ink colors when the latter item type is used as a carrier for the color.

Since the literature review provided by Jensen and Rohwer (1966), experimental work with the Stroop color-word test has increased considerably. A review of recent work is provided by Dyer (1973). Among other applications, the Stroop task has been used to assess the activation of words in memory (Warren, 1972, 1974; Conrad, 1974). In these studies, the word in question is used as the carrier for the color in a Stroop task, and the amount of interference with ink-color naming it produces is taken to be an indicant of its state of activation in memory.

Since the work of Klein (1959), it has been known that the degree to which a concrete word is associated with a color will affect the amount of interference it produces when presented as an item in the Stroop task. BLOOD, for example, is strongly associated with the color red and produces long color-naming latencies when presented in an antagonistic color such as green. Scheibe, Shaver, and Carrier (1967) have shown that abstract words which are associated with a color (e.g., BELIEVE-blue) will also lengthen color-naming latency when presented in antagonistic colors.

It is apparent, then, that studies employing the Stroop task as a tool to study other factors, such as memory activation, should control for the degree of color association of the words used in the various experimental conditions. The object of the present study was to obtain color associations to the colors most commonly used in Stroop tasks for a fairly large pool of words.

\section{METHOD}

\section{Subjects}

Fifty male and 50 female students enrolled in graduate and undergraduate psychology courses at Columbia University participated in the experiment as part of a course requirement. Ss were run in groups ranging in size from 18 to 50 .

\section{Materials and Procedure}

The 72 words used in the study are shown in Table 1 . The words were arbitrarily divided into two 36-word groups (Groups A and B), and each group was presented on a separate sheet of paper in individual test booklets. Test instructions appeared on the first page of the booklet. Half the Ss of each sex received booklets with the page of Group A words first and the page of Group B words second; the remaining Ss received booklets with Group B first and Group A second. Ss were instructed to print the first letter of the color which best fit or corresponded to each word in a space provided after it on the response sheet. Color associations were restricted to red, blue, yellow, and green.

\section{RESULTS}

Normative response frequencies obtained for the 72 words are shown in Table 1. Using the normal approximation to the binomial and assuming $\mathrm{p}=.25$ for each color, it is possible to assess the probability that the

Table 1

Restricted Color Association Frequencies

\begin{tabular}{lrrrr}
\hline & \multicolumn{3}{c}{ Color } \\
\cline { 2 - 5 } Word & $\mathrm{R}$ & $\mathrm{B}$ & $\mathrm{Y}$ & $\mathrm{G}$ \\
\hline APPLE & 91 & 2 & 4 & 3 \\
ARTIST & 39 & 35 & 13 & 13 \\
AUNT & 18 & 15 & 34 & 33 \\
BABY & 20 & 38 & 34 & 8 \\
BASIC & 26 & 49 & 9 & 16 \\
BOND & 25 & 24 & 15 & 36 \\
BRAVE & 62 & 26 & 4 & 8 \\
BREAD & 2 & 13 & 75 & 10 \\
BUG & 12 & 26 & 24 & 38 \\
BUY & 17 & 21 & 17 & 45 \\
CATS & 16 & 15 & 41 & 28 \\
CENTER & 37 & 27 & 14 & 22 \\
CHAIR & 20 & 16 & 39 & 25 \\
CLEAN & 5 & 35 & 40 & 20 \\
COLD & 7 & 75 & 9 & 9 \\
COMB & 9 & 41 & 29 & 21 \\
CUT & 70 & 8 & 10 & 12 \\
DARK & 20 & 66 & 3 & 11 \\
DESK & 13 & 23 & 40 & 24 \\
DIME & 5 & 30 & 40 & 25 \\
DRAIN & 7 & 30 & 29 & 34 \\
DRINK & 19 & 36 & 30 & 15 \\
& & & &
\end{tabular}


Table 1 Continued

\begin{tabular}{|c|c|c|c|c|}
\hline \multirow[b]{2}{*}{ Word } & \multicolumn{4}{|c|}{ Color } \\
\hline & $\mathbf{R}$ & B & $\mathrm{Y}$ & G \\
\hline DRY & 10 & 25 & 50 & 15 \\
\hline DUST & 14 & 17 & 51 & 18 \\
\hline FAST & 57 & 12 & 17 & 14 \\
\hline FATHER & 19 & 48 & 9 & 24 \\
\hline FIGURE & 34 & 26 & 19 & 21 \\
\hline FIRE & 87 & 0 & 11 & 2 \\
\hline FLOWERS & 35 & 5 & 36 & 24 \\
\hline FRONT & 28 & 23 & 20 & 29 \\
\hline GIRL & 38 & 23 & 27 & 12 \\
\hline HARD & 31 & 36 & 16 & 17 \\
\hline KNOCK & 48 & 19 & 17 & 16 \\
\hline LOVE & 60 & 25 & 5 & 10 \\
\hline LOW & 3 & 41 & 26 & 30 \\
\hline MAD & 91 & 3 & 2 & 4 \\
\hline MATCH & 60 & 10 & 16 & 14 \\
\hline MUSIC & 19 & 48 & 15 & 18 \\
\hline NAIL & 28 & 29 & 23 & 20 \\
\hline NEEDLE & 27 & 35 & 28 & 10 \\
\hline ODD & 24 & 11 & 35 & 30 \\
\hline OYSTER & 6 & 34 & 50 & 10 \\
\hline PEACE & 6 & 58 & 19 & 17 \\
\hline PLAN & 11 & 39 & 16 & 34 \\
\hline PLATE & 11 & 33 & 36 & 20 \\
\hline QUEEN & 51 & 14 & 16 & 19 \\
\hline RAMP & 19 & 17 & 31 & 33 \\
\hline READ & 28 & 33 & 17 & 22 \\
\hline RIVER & 4 & 66 & 7 & 23 \\
\hline ROAD & 19 & 19 & 35 & 27 \\
\hline ROUGH & 62 & 12 & 10 & 16 \\
\hline RUG & 20 & 28 & 22 & 30 \\
\hline SALT & 11 & 24 & 53 & 12 \\
\hline SCORE & 43 & 22 & 19 & 16 \\
\hline SEED & 6 & 8 & 36 & 50 \\
\hline SHEEP & 4 & 16 & 52 & 28 \\
\hline SHORT & 13 & 22 & 31 & 34 \\
\hline SLEEP & 4 & 63 & 20 & 13 \\
\hline SONG & 18 & 44 & 22 & 16 \\
\hline SOUND & 35 & 28 & 16 & 21 \\
\hline SPIDER & 32 & 31 & 17 & 20 \\
\hline STAGE & 30 & 31 & 25 & 14 \\
\hline STRONG & 68 & 21 & 7 & 4 \\
\hline SWEET & 28 & 16 & 47 & 9 \\
\hline TIGER & 32 & 0 & 64 & 4 \\
\hline TONE & 21 & 45 & 20 & 14 \\
\hline TOP & 30 & 26 & 24 & 20 \\
\hline TOWN & 29 & 23 & 17 & 31 \\
\hline VIEW & 2 & 27 & 19 & 52 \\
\hline WIND & 12 & 60 & 21 & 7 \\
\hline WINDOWS & 3 & 48 & 31 & 18 \\
\hline WOMAN & 59 & 18 & 14 & 9 \\
\hline
\end{tabular}

Note $-R=$ red, $B=$ blue,$Y=$ yellow, and $G=$ green. frequency of association of a word with a particular color (f) is greater or less than one would expect by chance. For $\alpha=.05$, these values are $\mathrm{f} \geqslant 33, \mathrm{f} \leqslant 17$. For $\alpha=.01$, these values are $\mathrm{f} \geqslant 36, \mathrm{f} \leqslant 14$.

Sex differences in color association were assessed using chi-square tests for words showing high overall absolute differences in response frequencies for the two sexes. Words showing significant differences are: ROAD, $\mathrm{p}<.01$, RAMP, and CATS, both $p<.05$. Since the number of words showing differences at each significance level is approximately that to be expected by chance from 72 independent tests, response distributions by sex for these words are omitted.

\section{DISCUSSION}

As expected, substantial differences in the degree of association with the four colors were obtained for the 72 test words. This result reinforces the belief that unless other means of compensating for these differences are utilized, experiments using the Stroop test as a tool to study other factors must equate the degree of color association of the words in different experimental conditions.

\section{REFERENCES}

Conrad, C. Context effects in sentence comprehension: A study of the subjective lexicon. Memory \& Cognition, 1974, 2, $130-138$.

Dyer, F. N. The Stroop phenomenon and its use in the study of preceptual, cognitive, and response processes. Memory \& Cognition, 1973, 1, 106-120.

Jensen, A. R., \& Rohwer, W. D., Jr. The Stroop color-word test: A review. Acta Psychologica, 1966, 25, 36-93.

Klein, G. S. Semantic power measured through the interference of words with color-naming. American Journal of Psychology, $1964,77,576-588$.

Scheibe, K. E., Shaver, P. R., \& Carrier, S. C. Color association values and response interference on variants of the Stroop test. Acta Psychologica, 1967, 26, 286-295.

Stroop, J. R. Studies of interference in serial verbal reactions. Journal of Experimental Psychology, 1935, 18, 643-662.

Warren, R. E. Stimulus encoding and memory. Journal of Experim ental Psychology, 1972, 94, 90-100.

Warren, R. E. Association, directionality and stimulus encoding. Journal of Experimental Psy chology, 1974, 102, 151-158. 